\title{
Counting Sunda clouded leopards with confidence: incorporating individual heterogeneity in density estimates
}

\author{
Azlan Mohamed, Rahel Sollmann, Seth Timothy Wong, Jürgen Niedialla \\ Jesse F. A brams, Johnny Kissing and Andreas Wilting
}

\begin{abstract}
Even with intensive sampling effort, data often remain sparse when estimating population density of elusive species such as the Sunda clouded leopard Neofelis diardi. An inadequate number of recaptures can make it difficult to account for heterogeneity in detection parameters. We used data from large-scale camera-trapping surveys in three forest reserves in Sabah, Malaysian Borneo, to (1) examine whether a high-density camera-trap network increases the number of recaptures for females, which tend to be more difficult to detect, thus improving the accuracy of density estimates; (2) compare density estimates from models incorporating individual heterogeneity in detection parameters with estimates from the null model to evaluate its potential bias; and (3) investigate how the size of the camera-trap grid affects density and movement estimates. We found that individual heterogeneity could not be incorporated in the single-site data analysis and only conservative null model estimates could be generated. However, aggregating data across study sites enabled us to account for individual heterogeneity and we estimated densities of 1.27-2.82 individuals $/ 100 \mathrm{~km}^{2}, 2-3$ times higher than estimates from null models. In light of these findings, it is possible that earlier studies underestimated population density. Similar densities found in well-managed forest and recently selectively logged forest suggest that Sunda clouded leopards are relatively resilient to forest disturbances. Our analysis also revealed that cameratrapping grids for Sunda clouded leopard density estimations should cover large areas (c. $250 \mathrm{~km}^{2}$ ), although smaller grids could be appropriate if density or detectability are higher.
\end{abstract}

Keywords Borneo, camera trapping, density, heterogeneity, Neofelis diardi, Sabah, spatially explicit capture-recapture, Sunda clouded leopard

\footnotetext{
Azlan Mohamed* (Corresponding author, (D) orcid.org/0000-0003-3788-4383), Seth Timothy Wong, Jürgen Niedballa, Jesse F. Abrams (iD orcid.org/00000003-0411-8519) and ANdreas Wilting Leibniz Institute for Zoo and Wildlife Research, Alfred-Kowalke-Str. 17, 10315 Berlin, Germany

E-mail azlan.mohamed@gmail.com

Rahel Sollmann Department of Wildlife, Fish, and Conservation Biology, University of California Davis, Davis, USA

Johnny Kissing Sabah Forestry Department, Sandakan, Sabah, Malaysia

${ }^{*}$ Also at: WWF-Malaysia, Petaling Jaya, Selangor, Malaysia

Received 7 September 2018. Revision requested 6 November 2018.

Accepted 3 December 2018. First published online 19 September 2019.
}

Supplementary material for this article is available at https://doi.org/10.1017/So030605318001503

\section{Introduction}

The Sunda clouded leopard Neofelis diardi occurs in the 1 tropical forests of Borneo and Sumatra. Its precise geographical range is unknown, but forest cover data suggest the species could still be widespread in Borneo, particularly in the island's central forest block, whereas in Sumatra its distribution is probably restricted to the west and a few isolated areas in the eastern and central parts of the island (Hearn et al., 2015). Tropical rainforests have declined substantially on both islands, mainly as a result of agricultural expansion and habitat degradation (Gaveau et al., 2007; 2016). Although the extent of poaching of the Sunda clouded leopard is unknown, illegal hunting is an additional threat to the species' survival (Hearn et al., 2016). The Sunda clouded leopard is categorized as Vulnerable on The IUCN Red List of Threatened Species (Hearn et al., 2015), with its Bornean and Sumatran subspecies categorized as Endangered (Hearn et al., 2008; Sunarto et al., 2008).

Effective conservation management for the Sunda clouded leopard is hampered by the lack of essential information about the species' biology, population status and ability to survive in human-modified landscapes, particularly within logging concessions, where a large proportion of its remaining population probably occurs (Wilting et al., 2012; Hearn et al., 2017). This dearth of information is mainly a result of the species' partially nocturnal and elusive behaviour and low population densities (Sabah: 1.0-2.0 individuals/ $100 \mathrm{~km}^{2}$ (Brodie \& Giordano, 2012); 1 individual/100 km (Wilting et al., 2012); 1.4-3.1 individuals $/ 100 \mathrm{~km}^{2}$ (Hearn et al., 2017); Sumatra: 0.5-2.0 individuals $/ 100 \mathrm{~km}^{2}$ (Sollmann et al., 2014); Kalimantan: 1.0-4.5 individuals/ $100 \mathrm{~km}^{2}$ (Cheyne et al., 2013)). Four of these studies (Brodie \& Giordano, 2012; Wilting et al., 2012; Hearn et al., 2017, Sollmann et al., 2014) used spatially explicit capture-recapture, which models individuals' locations and movement (Borchers \& Efford, 2008; Efford et al., 2009). In contrast, Cheyne et al. (2013) used a conventional capture-recapture model, which often overestimates densities, particularly for wide-ranging species, because animal movements and the 
ad-hoc assigned buffer width are underestimated (Singh et al., 2014). Because captures and recaptures are rare, these studies were unable to account for individual or sex-specific heterogeneity in detection, although studies on solitary felids have shown that males generally travel further than females and are thus more frequently exposed to traps (tiger Panthera tigris, Karanth \& Sunquist, 2000; jaguar Panthera onca, Sollmann et al., 2011). Accounting for this heterogeneity requires a larger sample size (Sollmann et al., 2011; Tobler \& Powell, 2013), which is often unavailable for elusive carnivores with low population densities (Howe et al., 2013).

Female clouded leopards are particularly difficult to detect. Of 39 mainland clouded leopards detected in a cameratrapping study in Peninsular Malaysia, only five were females (Mohamad et al., 2015). Other studies also recorded females much less frequently than males and usually only at a single trap (Wilting et al., 2012; Sollmann et al., 2014). Failure to account for such variation in detection probability between males and females, or more generally amongst individuals, can lead to underestimation of density because the sample is dominated by individuals with high detection probabilities.

Recommendations to address this issue include increasing survey effort by extending the survey area, increasing the density of camera traps, or extending the survey period as long as the closure assumption is not violated, as demonstrated in a number of simulation studies (Sollmann et al., 2012; Tobler \& Powell, 2013; Sun et al., 2014) and further supported by field data (Sollmann et al., 2011; Zimmermann et al., 2013). Covering large areas is logistically challenging in tropical forests, and previous studies on the Sunda clouded leopard only covered $75-160 \mathrm{~km}^{2}$, which could be too small for a species that occurs at low densities and with home ranges $>50 \mathrm{~km}^{2}$ for some males (the minimum convex polygons around cameras detecting the three males in this study covered $40-90 \mathrm{~km}^{2}$ ). The estimates derived from minimum convex polygons around camera-trap stations tend to underestimate home range size (Dillon \& Kelly, 2008), so the males' true home ranges could be larger. In logistically challenging terrain, increasing the area sampled may extend the overall survey duration, thereby risking violation of the population closure assumption. A more feasible approach is to combine data from multiple surveys (Tobler et al., 2013). This, however, is only beneficial when at least some parameters can be shared across surveys. Another possibility involves using a clustered design (Efford \& Fewster, 2013; Sun et al., 2014) in which high-density clusters of traps are distributed across a larger study area. Recaptures within clusters allow estimation of detection parameters, and the larger area coverage exposes more individuals to trapping efforts, potentially increasing the likelihood of spatial recaptures (i.e. recaptures at different localities) of individuals with smaller home ranges, such as females.

We surveyed Sunda clouded leopards in three Bornean forest reserves with different management histories, applying a modification of the clustered design in two of these areas. This allowed us to explore the effect of sampling design and the ability to model individual heterogeneity (i.e. between sexes or between latent groups of individuals; e.g. dominant and subdominant males) in detection on density estimates. Specifically, we (1) examine whether a high-density cameratrap network increases the number of recaptures for female Sunda clouded leopards and, thus, improves the accuracy of the density estimates; (2) compare density estimates from models that incorporate individual heterogeneity with estimates from a null model, to evaluate its potential bias; and (3) investigate how the size of the camera-trapping grid affects density and movement estimates. Based on our results, we make recommendations for future surveys. The large datasets from three reserves under different forest management allowed us also to investigate the impact of different logging regimes on Sunda clouded leopard densities and, thus, contribute to the ecological understanding of this threatened felid.

\section{Study area}

We conducted our study in three forest reserves with different management histories that form a continuous forest block in central Sabah, Malaysian Borneo (Fig. 1): Deramakot, Tangkulap-Sungai Talibu and Northern Kuamut. All sites are predominantly mixed lowland dipterocarp forest, with Northern Kuamut having a higher proportion of upland dipterocarp forests above $500 \mathrm{~m}$ than the others. The sites receive $2,500-3,500 \mathrm{~mm}$ of annual rainfall, with no apparent wet or dry seasons.

Deramakot (c. $\left.551 \mathrm{~km}^{2}\right)$ is managed in accordance with sustainable forestry principles, applies only reduced-impact logging and has been certified by the Forest Stewardship Council since 1997 (Lagan et al., 2007). In contrast, conventional selective logging practices were historically applied in Tangkulap-Sungai Talibu and Northern Kuamut. Logging in Tangkulap-Sungai Talibu (c. $500 \mathrm{~km}^{2}$ ) ceased in 2001. In 2011, it received Forest Stewardship Council certification, and was designated as a protected area in 2015. Northern Kuamut (c. $\left.650 \mathrm{~km}^{2}\right)$ is heavily degraded as a result of conventional logging during 2004-2012. In 2015 it was declared a totally protected area. Oil palm plantations border the study sites to the north and east of Northern Kuamut, and to the north of Deramakot and Tangkulap-Sungai Talibu. We found limited evidence of hunting in these sites, suggesting that poaching pressure is low.

\section{Methods}

\section{Camera-trapping protocol}

We conducted a two-phase camera-trapping survey with a coarse- and a fine-grid network in Deramakot (during 


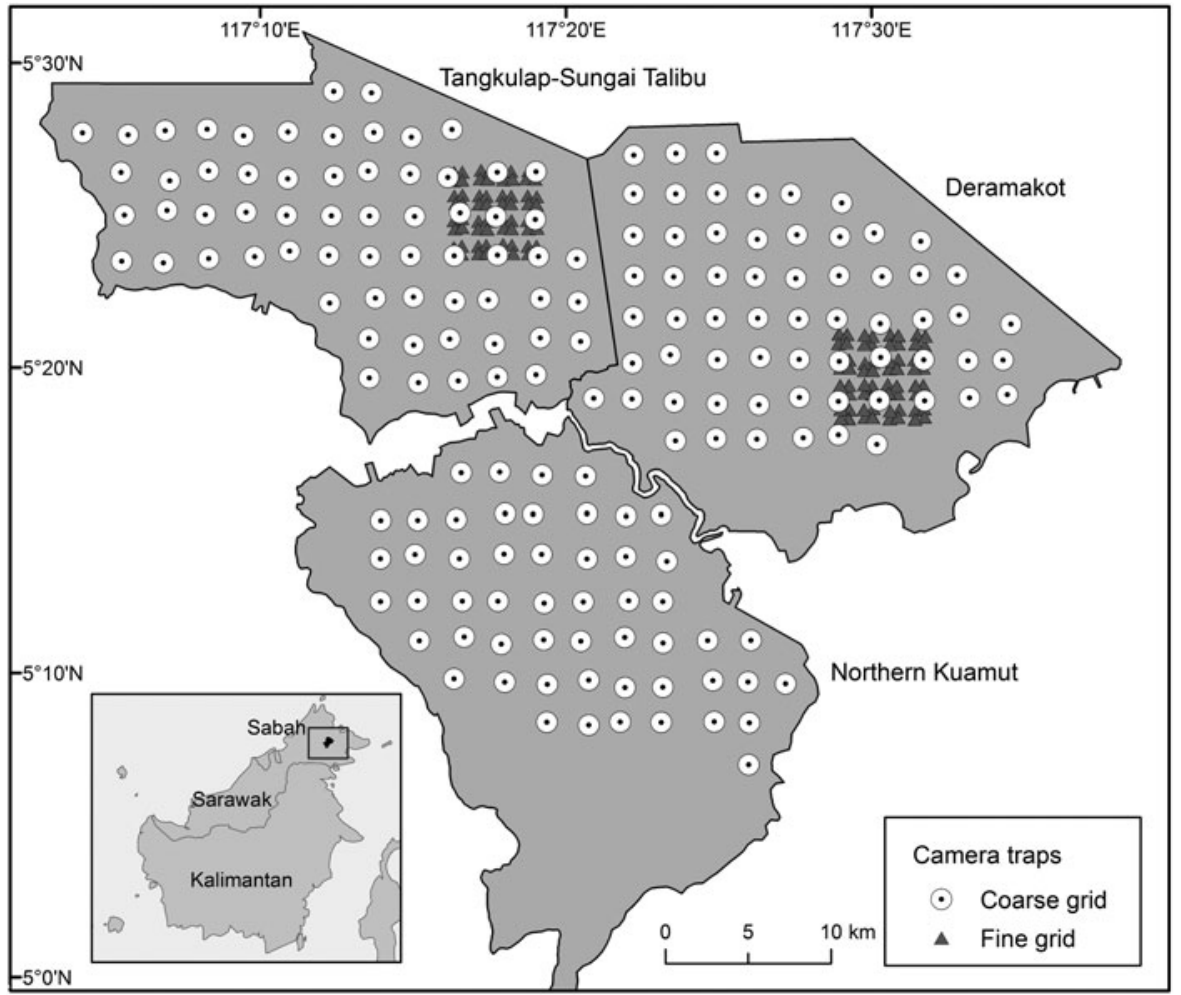

FIG. 1 Location of camera-trap stations for the coarse grid $(2.2 \mathrm{~km}$ spacing between cameras) and fine grid in clustered design $(0.5 \mathrm{~km}$ spacing within the cluster and $1.5 \mathrm{~km}$ spacing between cluster centres) in Deramakot, Tangkulap-Sungai Talibu and Kuamut Forest Reserves, Malaysian Borneo.
September 2014-May 2015) and Tangkulap-Sungai Talibu (during July 2015-February 2016). Northern Kuamut was sampled during March-July 2016, using only a coarse-grid design. For the coarse-grid surveys, we set 63 (Deramakot), 64 (Tangkulap-Sungai Talibu) and 53 (Northern Kuamut) camera stations, each consisting of two Reconyx PC850 cameras (Reconyx Inc., Holmen, USA). Within a station, cameras often targeted different trails, but were placed within $20 \mathrm{~m}$ of each other. We set cameras at a height of $30-45 \mathrm{~cm}$ along animal trails, old logging roads or on ridgelines, to maximize detection probability of Sunda clouded leopards. Because females may avoid traveling on larger trails and logging-related features (Wearn et al., 2013), we set one camera for each station along a smaller path whenever possible. Coarse-grid stations were spaced at $2.5 \mathrm{~km}$, resulting in trapping areas of c. $400 \mathrm{~km}^{2}$ each (Table 1 ).

In Deramakot and Tangkulap-Sungai Talibu, coarse-grid surveys were followed by fine-grid surveys in an area where at least one female Sunda clouded leopard had been recorded. Specifically, we deployed cameras in a clustered design, with each cluster consisting of a square of four stations spaced $500 \mathrm{~m}$ apart. Each station had two cameras facing each other, to photograph both flanks of a passing animal. We established 16 clusters in a $4 \times 4$ configuration, spacing clusters (centre to centre) c. $1.5 \mathrm{~km}$ apart (Fig. 1). With these fine-grid surveys we aimed to increase the number of recaptures of females, which are difficult to record and have smaller ranges of c. $16 \mathrm{~km}^{2}$ (Hearn et al., 2013). Although we detected two and three additional females during the fine-grid surveys in Deramakot and Tangkulap-Sungai Talibu, respectively (Table 1 ), none of these females were recorded more than once. Therefore, these captures did not improve the estimation of female movement and thus densities. Consequently, we decided it was not worth repeating a similar effort in Northern Kuamut. During each phase cameras were left for 60-100 days, and were operational continuously.

\section{Data preparation and analysis}

We analysed camera-trap data and constructed a spatial detection history using the $R$ package camtrap $R$ (Niedballa et al., 2016). Two researchers carried out individual identification of Sunda clouded leopards and we only included detections if both agreed on the individual identity. Individuals and sex were identified using the unique pelage patterns and secondary sexual traits; i.e. genital portion and tail (females have thicker and fluffier tails than males). We first created a reference collection of two-sided photos obtained from coarse- and fine-grid surveys, as well as from earlier surveys. For all individuals for which we could only obtain single-sided photos, we used the side with the highest number of records and discarded the other side, to avoid double counting. We estimated population density of Sunda clouded leopards with a maximum-likelihood-based spatially explicit capturerecapture approach, using the secr package (Efford, 2016) 
TABLE 1 Summary of camera-trapping surveys and Sunda clouded leopard Neofelis diardi records in Deramakot, Tangkulap-Sungai Talibu and Northern Kuamut for coarse-grid and fine-grid surveys. Detection records for unidentified individuals are not included in this table.

\begin{tabular}{|c|c|c|c|}
\hline & $\begin{array}{l}\text { Deramakot Forest } \\
\text { Reserve }\end{array}$ & $\begin{array}{l}\text { Tangkulap-Sungai Talibu } \\
\text { Forest Reserve }\end{array}$ & $\begin{array}{l}\text { Northern Kuamut } \\
\text { Forest Reserve }\end{array}$ \\
\hline \multicolumn{4}{|l|}{ Coarse-grid survey information } \\
\hline Survey period & Sep. 2014-Jan. 2015 & July 2015-Nov. 2015 & Mar. 2016-July 2016 \\
\hline Stations & 63 & 64 & 53 \\
\hline Camera days & 4,465 & 4,294 & 3,522 \\
\hline Area $^{1}\left(\mathrm{~km}^{2}\right)$ & 424 & 478 & 372 \\
\hline \multicolumn{4}{|l|}{ Fine-grid survey information } \\
\hline Survey period & Feb. 2015-May 2015 & Nov. 2015-Feb. 2016 & \\
\hline Stations & 64 & 64 & \\
\hline Camera days & 4,041 & 3,964 & \\
\hline $\operatorname{Area}^{1}\left(\mathrm{~km}^{2}\right)$ & 57 & 56 & \\
\hline \multicolumn{4}{|c|}{ Sunda clouded leopard information (coarse grid) } \\
\hline Individuals & 11 & 5 & 8 \\
\hline Independent records & 32 & 15 & 17 \\
\hline Sex composition ${ }^{2}$ & $6 \mathrm{M}, 5 \mathrm{~F}$ & $4 \mathrm{M}, 1 \mathrm{~F}$ & $6 \mathrm{M}, 2 \mathrm{~F}$ \\
\hline Mean number of detections by $\operatorname{sex}^{2}$ (range) & $4.0(1-13) \mathrm{M}$, & $3.25(2-7) \mathrm{M}$, & $2.3(2-4) \mathrm{M}$, \\
\hline \multicolumn{4}{|c|}{ Sunda clouded leopard information (coarse and fine grid) } \\
\hline Individuals & 13 & 8 & 8 \\
\hline Independent records & 43 & 25 & 17 \\
\hline Sex composition ${ }^{2}$ & $6 \mathrm{M}, 7 \mathrm{~F}$ & $4 \mathrm{M}, 4 \mathrm{~F}$ & $6 \mathrm{M}, 2 \mathrm{~F}$ \\
\hline Mean number of detections by $\operatorname{sex}^{2}$ (range) & $5.17(1-15) \mathrm{M}$ & $\begin{array}{l}5.0(2-13) \mathrm{M} \text {, } \\
125(1-2) \mathrm{F}\end{array}$ & $2.3(2-4) \mathrm{M}$, \\
\hline
\end{tabular}

${ }^{1}$ Minimum convex polygon around camera-trap stations.

${ }^{2} \mathrm{M}$, male; F, female.

in $R$ 3.3.3 (R Core Team, 2017). Spatially explicit capturerecapture models use the locations of individual detections to estimate density, accounting for variation in exposure to sampling. Detection is modelled as a decreasing function of distance between an individual's activity centre and a given trap. We used the most common, half-normal detection function, which is described by two parameters: go, the probability of capture at the activity centre of an individual, and $\sigma$, the spatial scale parameter that describes the decline in probability of capture with distance from the activity centre (Efford et al., 2009; Efford \& Fewster, 2013). In both the coarse and fine grid, we treated the two cameras at each station as one single station, which we considered operational if at least one camera was functional. Our sampling duration is comparable to other studies on the Sunda clouded leopard, to approximate a closed population (Wilting et al., 2012; Hearn et al., 2017). We defined each day as one sampling occasion. When a station was not operational, we set the effort for that station and occasion to zero. We used Poisson observation models, and defined the state space for each site by adding a $30-\mathrm{km}$ buffer, which is five times the estimated $\sigma$ from a previous study in Sabah (Wilting et al., 2012). We present results as means \pm SE and $95 \%$ confidence intervals. Parameters were considered to be significantly different from each other when their $95 \%$ confidence intervals did not overlap.
Does the fine-grid survey improve density estimates?

To evaluate whether a high-density camera-trap network improved the accuracy of density estimates for Deramakot and Tangkulap-Sungai Talibu, we combined data from the coarse and fine grid and fit multi-session models, with sessions representing males and females. Because we were interested in how much the fine grid improves estimates at a single site, we ran a multi-session model for each site and fitted models that allowed for sex-specific density, go and $\sigma$. We also fitted a model that held parameters constant and compared the models using Akaike's information criterion corrected for small sample size (AICc).

\section{Density of Sunda clouded leopards}

To estimate densities in all sites, we used only the data from the coarse grid because the fine grid did not increase the number of female recaptures and because this standardized data collection across sites. Including fine-grid data would have doubled the study duration in Deramakot and Tangkulap-Sungai Talibu; as movement is estimated over the course of the study, this would have hampered sharing estimates for $\sigma$ across sites. Plotting the spatial distribution of captures and recaptures of all individuals (Fig. 2) indicated that heterogeneity in movement existed not only between 


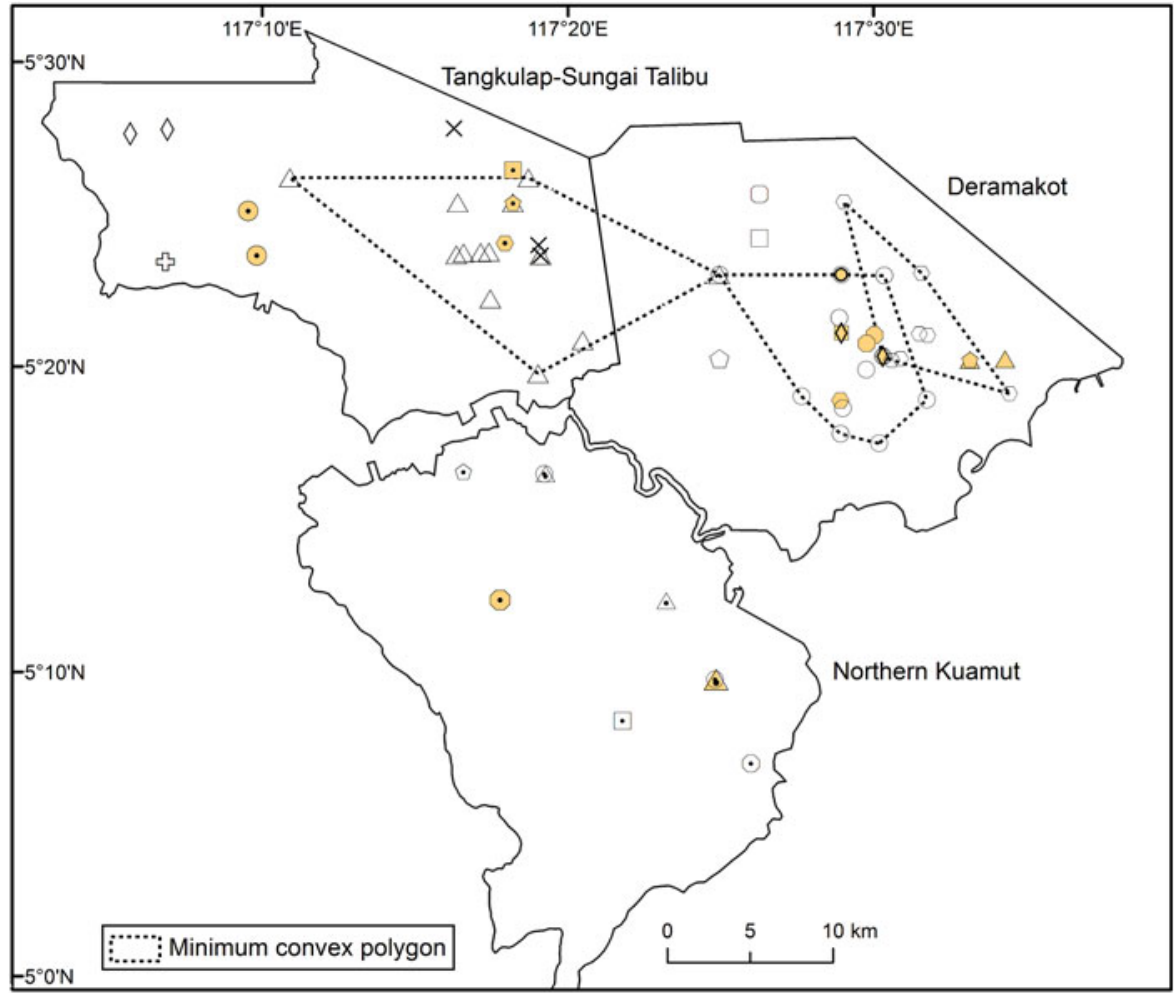

FIG. 2 Locations of individual Sunda clouded leopards Neofelis diardi that were recorded in all three reserves. Filled symbols represent females, other symbols represent males, and shapes represent different individuals. males and females, but also amongst males. Two males from Deramakot and one from Tangkulap-Sungai Talibu moved much larger distances than other males. The population may therefore be better represented as a mixture of two types of individuals: dominant males who move over large areas and are detected frequently, and subordinate males and females who are more elusive and range over smaller areas. Because dominance status cannot be determined from photographs in the same manner as sex, we modelled individual heterogeneity in movement and baseline detection using a finite mixture model (Pledger, 2000; Borchers \& Efford, 2008) that assigns individuals to two latent groups. In this analysis, sites were modelled as sessions that represent independent closed-population surveys (i.e. closure is assumed for each survey). Evidence for non-independence was weak with only one individual recorded at multiple sites, and we assigned this individual a different identification for each site. We allowed density to vary between the sessions/ sites, whereas detection parameters were kept constant across sites. We also fitted two models with sex as a covariate instead of the mixture, one sharing detection parameters across surveys and one with session and sex as additive effects, as well as a model with the two-group mixture and session as an additive effect. These models had considerably lower AICc support than the mixture model with shared detection parameters (Supplementary Table 1). We therefore only compared results from the mixture model with estimates from a null model, to evaluate the implications of ignoring individual heterogeneity in detection parameters. We further use results from these analyses to discuss the impacts of different logging regimes on Sunda clouded leopard densities.

\section{Effect of the size of area surveyed}

To evaluate how large a survey area needs to be to yield reliable estimates of Sunda clouded leopard density, we used data from the Deramakot coarse grid where we recorded the highest number of individuals and recaptures. Of the 63 stations, we subsampled 21 and 42 stations from either the centre, southwest, south-east, north-west or north-east corners (scenarios 1-5 and 7-11). In addition, we subsampled stations to create a clustered design consisting of five camera-trap clusters with $4 / 8$ stations located in each corner plus 5/10 stations in the centre (scenarios 6 and 12). For each scenario, we estimated density including only individuals/detections from the selected camera-trap stations in the respective subset. We then compared these analyses with our density estimate from the full data set (all 63 stations; scenario 13) in Deramakot. Because data from subsamples were sparse, we ran only null models for all scenarios.

\section{Results}

\section{Detection and movement data}

We obtained 98 independent records of Sunda clouded leopards from all reserves during the coarse- and fine-grid 
surveys (20,286 camera days total). We discarded six singlesided photographs (three records each from the coarse and the fine grid) that could not be identified. From the coarse grid, we identified 11 individuals in Deramakot (6 males, 5 females), five individuals in Tangkulap-Sungai Talibu (4 males, 1 female) and eight individuals in Northern Kuamut (6 males, 2 females; Table 1). The fine-grid surveys in Deramakot and Tangkulap-Sungai Talibu captured two and three additional females, respectively, but did not increase the number of recaptures for females. There were noticeable differences in the spatial distribution of detections between males (Fig. 2). In Deramakot two males together accounted for $56 \%$ of the total number of records, and in Tangkulap-Sungai Talibu one male accounted for $46 \%$ of the total records. Other males and females were only recorded between 1-3 times at a maximum of two stations.

\section{Does the fine-grid survey improve density estimates?}

Although the number of captured females was increased by combining coarse- and fine-grid surveys, sparse recapture data still hindered estimation of sex-specific detection parameters. In the model that allowed $\sigma$ and go to vary with sex, $\sigma$ for females could not be estimated for Tangkulap-Sungai Talibu (19.421 \pm SE $159.180 \mathrm{~km}$; Table 2) because of insufficient recaptures. Deramakot sex-specific models performed better than the null model, based on AICc, and the estimate of $\sigma$ for females was more reasonable $(2.300 \pm$ SE $4.015 \mathrm{~km})$. However, female densities were estimated to be ten times higher than male densities (5.482 \pm SE 2.949 individuals/ $100 \mathrm{~km}^{2}$ for females and $0.580 \pm \mathrm{SE} 0.291$ for males), which is unlikely to be the sex ratio in a wild population (Jenny, 1996). When detection parameters were shared across sites, parameters for Tangkulap-Sungai Talibu became estimable, but sex ratios remained ecologically unreasonable (Supplementary Table 2).

\section{Density of Sunda clouded leopards}

The null model for the coarse-grid data showed that density of Sunda clouded leopards was higher in Northern Kuamut with $1.22 \pm \mathrm{SE} 0.61$ individuals $/ 100 \mathrm{~km}^{2}$, followed by Deramakot at $0.89 \pm \mathrm{SE} 0.42$ and Tangkulap-Sungai Talibu at $0.39 \pm$ SE 0.25 individuals $/ 100 \mathrm{~km}^{2}$. The $95 \%$ confidence intervals for all sites overlapped, indicating that the differences were not statistically significant (Table 3). Estimates of $\sigma$ in Deramakot and Tangkulap-Sungai Talibu were similar, at $5.99 \pm \mathrm{SE} 1.49 \mathrm{~km}$ and $6.00 \pm \mathrm{SE}$ $1.83 \mathrm{~km}$, respectively; in Northern Kuamut, $\sigma$ was $4.47 \pm \mathrm{SE}$ $1.16 \mathrm{~km}$. The baseline trap encounter rate, $g o$, was almost identical for all sites with $0.004 \pm$ SE 0.001 in Deramakot, $0.004 \pm$ SE 0.002) in Tangkulap-Sungai Talibu, and $0.003 \pm$ SE 0.001 in Northern Kuamut. The mixture model tripled density estimates in Deramakot and Tangkulap-Sungai Talibu to $2.8 \pm$ SE 1.11 and $1.27 \pm$ SE 0.68 individuals/ $100 \mathrm{~km}^{2}$, respectively, and doubled density estimates in Northern Kuamut to $2.42 \pm$ SE 1.09 individuals $/ 100 \mathrm{~km}^{2}$ (Table 3). Nearly $92 \%$ of all individuals were assigned to the first mixture with lower $\sigma(0.74 \pm \mathrm{SE} 0.11 \mathrm{~km})$, and higher go (0.03 $\pm \mathrm{SE}$ 0.01). In the second mixture $\sigma$ was $7.44 \pm \mathrm{SE}$ $1.75 \mathrm{~km}$ and $g o$ was $0.005 \pm$ SE 0.002 . The $95 \%$ confidence intervals of $\sigma$ and go between these two groups did not overlap. Based on AICc, the mixture model was favored $($ AICc $=936 ;$ null model AICc $=990)$.

\section{Effect of the size of area surveyed}

Including all 63 stations, the survey area in Deramakot was $424 \mathrm{~km}^{2}$, the density estimate under the null model was 0.89 \pm SE 0.42 individuals $/ 100 \mathrm{~km}^{2}, \sigma$ was estimated to be $5.99 \pm$ SE $1.48 \mathrm{~km}$ and the estimate for go was $0.004 \pm \mathrm{SE} 0.001$. With 21 stations, the surveyed area was $120-140 \mathrm{~km}^{2}$. The number of individuals captured was 3-6 and density was $0.52-7.72$ individuals $/ 100 \mathrm{~km}^{2}$ with wide confidence intervals (Fig. 3, Supplementary Table 3). The estimate for $\sigma$ was $0.39-8.83 \mathrm{~km}$ and for $g_{0}$ it was $0.003-1.92$. For 42 station subsets, the surveyed area was $265-280 \mathrm{~km}^{2}$ and the number of individuals captured for each subset was 7-11. Densities were $0.47-1.65$ individuals $/ 100 \mathrm{~km}^{2}, \sigma$ was $4.56-7.89 \mathrm{~km}$ and go was $0.004^{-0.007}$.

\section{Discussion}

\section{Increasing confidence in density estimates}

Several studies have provided recommendations for improving density estimates of large carnivores, including large survey efforts and incorporating individual covariates (e.g. sex) in the analysis (Sollmann et al., 2011; Tobler \& Powell, 2013). Here, we used a trapping polygon $>370 \mathrm{~km}^{2}$, twice the size of that used in previous studies and at least seven times the likely size of male clouded leopard home ranges, and kept survey duration short enough ( $<100$ days $)$ to approximate population closure. Our trap spacing was close enough $(<2 \sigma)$ to detect individuals at multiple traps (following Sollmann et al., 2012 and Sun et al., 2014). The fine grid was designed specifically to target females, which are thought to have much smaller home ranges and a much lower detection probability. But despite the extensive coarse-grid and locally intensive fine-grid surveys, our single-site data remained too sparse to include sex as a covariate, or model detection heterogeneity using finite mixture models.

Although behavioural differences (i.e. movement patterns) between the sexes, which translate into differences in detectability, have been reported for other large felids 
TABLE 2 Summary of sex-specific models from coarse- and fine-grid surveys in Deramakot and Tangkulap-Sungai Talibu, ranked by difference in Akaike's information criterion corrected for small sample size ( $\triangle \mathrm{AICc})$, with corresponding AICc of each model. We ran a multi-session model for each site, with sessions representing males $(\mathrm{M})$ and females $(\mathrm{F})$. For each model density estimate (D), movement parameter $(\sigma)$, and baseline trap encounter rate ( $g o$, photographs per occasion) are shown. The $\sim$ symbol is an $R$ formula notation used in the model specification to express the effect of covariate on parameters.

\begin{tabular}{|c|c|c|c|c|c|}
\hline Model & $\begin{array}{l}\mathrm{D} \pm \mathrm{SE} \\
\text { (individuals } / 100 \mathrm{~km}^{2} \text { ) }\end{array}$ & $\sigma \pm \mathrm{SE}(\mathrm{km})$ & $g 0 \pm \mathrm{SE}$ & AICc & $\Delta \mathrm{AICc}$ \\
\hline \multicolumn{6}{|l|}{ Deramakot Forest Reserve } \\
\hline \multirow[t]{2}{*}{$\mathrm{D} \sim$ session, $\sigma \sim$ session, $g 0 \sim$ session } & $0.580 \pm 0.291 \mathrm{M}$ & $5.001 \pm 1.014 \mathrm{M}$ & $0.004 \pm 0.001 \mathrm{M}$ & 693.539 & 0.000 \\
\hline & $5.482 \pm 2.946 \mathrm{~F}$ & $1.019 \pm 0.236 \mathrm{~F}$ & $0.003 \pm 0.002 \mathrm{~F}$ & & \\
\hline \multirow[t]{2}{*}{$\mathrm{D} \sim 1, \sigma \sim$ session, $g 0 \sim$ session } & $2.488 \pm 0.809$ & $4.302 \pm 0.657 \mathrm{M}$ & $0.004 \pm 0.001 \mathrm{M}$ & 696.919 & 3.380 \\
\hline & & $1.164 \pm 0.315 \mathrm{~F}$ & $0.005 \pm 0.003 \mathrm{~F}$ & & \\
\hline $\mathrm{D} \sim 1, \sigma \sim 1, g 0 \sim 1$ & $1.267 \pm 0.620$ & $5.473 \pm 1.485$ & $0.002 \pm 0.0007$ & 704.493 & 10.954 \\
\hline \multicolumn{6}{|c|}{ Tangkulap-Sungai Talibu Forest Reserve } \\
\hline $\mathrm{D} \sim 1, \sigma \sim 1, g 0 \sim 1$ & $0.494 \pm 0.293$ & $7.101 \pm 1.986$ & $0.003 \pm 0.001$ & 420.826 & 0.000 \\
\hline \multirow[t]{2}{*}{$\mathrm{D} \sim 1, \sigma \sim$ session, $g 0 \sim$ session } & $0.475 \pm 0.443$ & $6.980 \pm 2.215 \mathrm{M}$ & $0.004 \pm 0.002 \mathrm{M}$ & 442.721 & 21.895 \\
\hline & & $19.421 \pm 159.180 \mathrm{~F}$ & $0.0001 \pm 0.0003 \mathrm{~F}$ & & \\
\hline \multirow[t]{2}{*}{$\mathrm{D} \sim$ session, $\sigma \sim$ session, $g 0 \sim$ session } & $0.226 \pm 0.173 \mathrm{M}$ & $7.077 \pm 2.107 \mathrm{M}$ & $0.004 \pm 0.002 \mathrm{M}$ & 497.359 & 76.533 \\
\hline & $4.906 \pm 24.597 \mathrm{~F}$ & $2.300 \pm 4.015 \mathrm{~F}$ & $0.0003 \pm 0.0005 \mathrm{~F}$ & & \\
\hline
\end{tabular}

such as the tiger Panthera tigris (Singh et al., 2014) and jaguar Panthera onca (Sollmann et al., 2011), this contrast appears to be particularly pronounced in Sunda clouded leopards. This could be a result of the species' arboreal habits, with females spending more time in trees than males, which reduces their detection probability with groundbased camera traps. The species exhibits strong sexual dimorphism, with males often weighing twice as much as females (Hearn et al., 2013), which supports this hypothesis. A targeted design, with a portion of cameras along branches of large trees (Bowler et al., 2016), or in places where the animals need to descend because of impassable canopy gaps, may increase the number of detections of females. However, collecting sufficient data at a single study site to account for sex-specific heterogeneity in detection would probably remain a challenge. In addition, accounting only for sex may be insufficient because there is pronounced heterogeneity amongst males (Table 3). Intrasexual heterogeneity has been documented in other carnivores such as the American black bear Ursus americanus, for which individual differences were clearly evident in a female-only data set (Howe et al., 2013). The high level of heterogeneity in detection probabilities can thus be caused by factors other than sex, including age, social status and habitat features (Cubaynes et al., 2010).

One way to increase sample size, which allowed us to model heterogeneity in detectability, is to share detection parameters across multiple sites. Our analysis using finite mixture models revealed that incorporating individual heterogeneity strongly affects model results, as density estimates increased substantially compared to the null model. This is probably the result of the smaller estimates of the movement parameter for one of the groups, compared to the null models in which $\sigma$ is probably biased by the large movements of a few individuals. In our study, three individuals were captured five or more times, at more than three stations, but most individuals, including all females and 13 males, were captured only once or twice. In large solitary felids, established dominant males usually have a greater chance of being recaptured by camera traps than subordinate or transient males (Karanth et al., 2006). Our results indicate that a finite mixture model is a suitable approach when an observable, binary covariate such as sex does not fully describe heterogeneity, but works only if sample size is sufficiently large. However, this model still does not capture the full range of complexities. For instance, although some males were grouped together with females, their home ranges may be substantially larger than that of females, but as subordinate males they may avoid the travel routes of dominant males and thus have lower detection probabilities. Similarly, transient males may also have lower detection probabilities because they will probably not be recaptured. Additional data on the movement ecology of dominant and subordinate male and female Sunda clouded leopards would be needed to evaluate our findings. Our attempt to implement the mixture model on single site data sets led to unreliable results and some models did not converge because of sparse data. Considering the low population densities of Sunda clouded leopards, aggregating data across several study sites is probably necessary to successfully apply this modelling approach. Surveys of a single site are unlikely to obtain sufficient data to account for heterogeneity in detection.

Unmodelled heterogeneity can lead to inaccurate population estimates from capture-recapture models (Otis et al., 1978), including spatially explicit capture-recapture (Sollmann et al., 2011). However, for single site studies with sparse data sets, conservative estimates that ignore 
TABLE 3 Summary of site-specific spatial capture-recapture analysis using null models and mixture model. For each model density estimate (D), movement parameter $(\sigma)$, and baseline trap encounter rate (go, photographs per occasion) are shown. The $\sim$ symbol is an $R$ formula notation used in the model specification to express the effect of covariate on parameters.

\begin{tabular}{|c|c|c|}
\hline Parameters & Mean \pm SE & $95 \% \mathrm{CI}$ \\
\hline \multicolumn{3}{|c|}{ Null model, $\mathrm{D} \sim$ session, $g 0 \sim$ session, $\sigma \sim$ session } \\
\hline \multicolumn{3}{|c|}{ Deramakot Forest Reserve } \\
\hline$\sigma$ & $5.992 \pm 1.478$ & $3.720-9.645$ \\
\hline$g 0$ & $0.004 \pm 0.001$ & $0.002-0.008$ \\
\hline $\mathrm{D}$ & $0.888 \pm 0.424$ & $0.365-2.157$ \\
\hline \multicolumn{3}{|c|}{ Tangkulap-Sungai Talibu Forest Reserve } \\
\hline$\sigma$ & $5.997 \pm 1.829$ & $3.343-10.75$ \\
\hline g0 & $0.004 \pm 0.002$ & $0.002-0.011$ \\
\hline $\mathrm{D}$ & $0.387 \pm 0.254$ & $0.120-1.252$ \\
\hline \multicolumn{3}{|c|}{ Northern Kuamut Forest Reserve } \\
\hline$\sigma$ & $4.472 \pm 1.158$ & $2.714-7.368$ \\
\hline$g 0$ & $0.003 \pm 0.001$ & $0.001-0.008$ \\
\hline $\mathrm{D}$ & $1.221 \pm 0.605$ & $0.487-3.059$ \\
\hline \multicolumn{3}{|c|}{ Mixture model, $\mathrm{D} \sim$ session, $g 0 \sim \mathrm{h} 2, \sigma \sim \mathrm{h} 2$} \\
\hline \multicolumn{3}{|l|}{ All sites } \\
\hline$\sigma$ (group1) & $0.742 \pm 0.110$ & $0.556-0.991$ \\
\hline$g 0($ group 1$)$ & $0.031 \pm 0.010$ & $0.016-0.059$ \\
\hline $\operatorname{pmix}^{1}$ (group1) & $0.920 \pm 0.048$ & $0.764-0.976$ \\
\hline$\sigma$ (group2) & $7.442 \pm 1.746$ & $4.728-11.716$ \\
\hline$g 0$ (group2) & $0.005 \pm 0.002$ & $0.003-0.009$ \\
\hline $\operatorname{pmix}^{1}$ (group2) & $0.080 \pm 0.048$ & $0.024-0.236$ \\
\hline \multicolumn{3}{|c|}{ Deramakot Forest Reserve } \\
\hline $\mathrm{D}$ & $2.824 \pm 1.107$ & $1.346-5.926$ \\
\hline \multicolumn{3}{|c|}{ Tangkulap-Sungai Talibu Forest Reserve } \\
\hline $\mathrm{D}$ & $1.268 \pm 0.683$ & $0.472-3.408$ \\
\hline \multicolumn{3}{|c|}{ Northern Kuamut Forest Reserve } \\
\hline $\mathrm{D}$ & $2.421 \pm 1.086$ & $1.046-5.605$ \\
\hline
\end{tabular}

${ }^{1}$ pmix, probability of belonging either to first or second group of individuals.

individual heterogeneity are often the only available option. Our data can therefore be used to put older null model estimates in perspective. Whereas our null model density estimates are comparable to previous studies that also applied spatially explicit capture-recapture analysis (Brodie \& Giordano, 2012; Wilting et al., 2012; Sollmann et al., 2014; Hearn et al., 2017), estimates that account for individual heterogeneity are 2-3 times higher. Although this cannot be generalized, it indicates that Sunda clouded leopard population densities may be higher than previously thought.

\section{Effect of the size of area surveyed}

In monitoring wildlife populations, precise density estimates are crucial to detect population changes and inform conservation management. Because both the number of individuals and recaptures greatly influence the precision of density estimates (Singh et al., 2014; Wilton et al., 2014), the survey area needs to be large enough to ensure that sufficient individuals are recorded. In addition, trap spacing needs to ensure that individuals can be recorded at multiple stations. For Sunda clouded leopards, our results suggest the area surveyed should be at least $250 \mathrm{~km}^{2}$. Density estimates for the 42-station subsets were closer to the full data set $(63$ stations) than 21-stations, and the precision of estimates also improved. In contrast, the smaller c. $130 \mathrm{~km}^{2}$ subset, corresponding approximately to areas surveyed in previous studies (Brodie \& Giordano, 2012; Wilting et al., 2012; Cheyne et al., 2013), showed large confidence intervals and considerable variation in density estimates between the subsets. This could be partly because of actual differences in density among the smaller subsets (large subsets had more spatial overlap, with estimates more likely to be similar even if density is spatially heterogeneous), but is probably also a result of sparse data. For species with high detection probability, a trapping grid of one home range might be sufficient (Sollmann et al., 2012), but as Sunda clouded leopards have low detection probability, an area the size of a male home range is too small to obtain precise density estimates. Survey areas of c. $250 \mathrm{~km}^{2}$, i.e. 3-11 times larger than male and female clouded leopard home ranges, are large enough to result in precise estimates, albeit under the null model. It is important to note that this recommendation is site specific and may not necessarily apply in areas with high Sunda clouded leopard densities, as shown in Hearn et al. (2017).

\section{Impact of selective logging on Sunda clouded leopard abundance}

Our results support previous studies that showed Sunda clouded leopard populations persist in logging concessions. The densities we report are consistent with previous estimates from Sabah (Brodie \& Giordano, 2012; Wilting et al., 2012), including estimates from a recent study that included surveys of primary rainforests (Hearn et al., 2017). The effects of different forest management regimes on Sunda clouded leopard populations were not consistent. Although density estimates from Tangkulap-Sungai Talibu, where logging ceased 15 years ago, were lower for both models compared to the sustainably managed forest reserve Deramakot, densities in recently logged forest in Northern Kuamut were similar to those in Deramakot. This partly contradicts the tentative findings from Hearn et al. (2017) who suggested that Sunda clouded leopard density may be positively related to time passed since logging stopped. Logging in our trapping area in Northern Kuamut ceased just a few years before our surveys, but was still ongoing in the south-east of this forest reserve at the time of the surveys. It is therefore also possible that high levels of disturbance in adjacent areas resulted in more transient individuals, increasing the numbers of individuals recorded (Larrucea et al., 2006). This hypothesis 

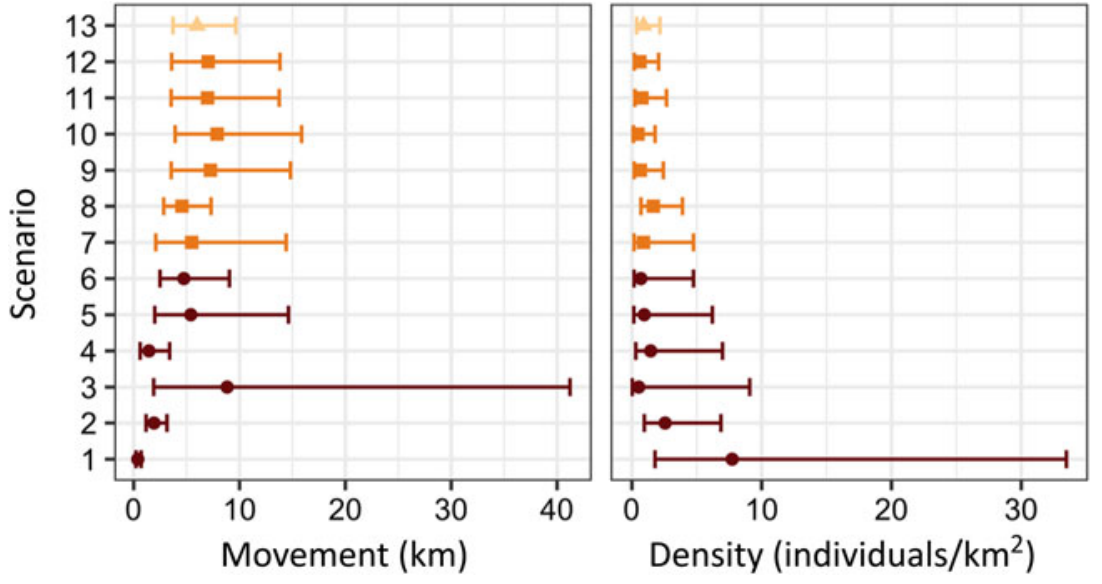

FIG. 3 Mean density and movement estimates for all scenarios, with $95 \%$ confidence interval. Scenarios 1-6 are subsets with 21 stations, scenarios 7-12 are subsets with 42 stations and scenario 13 uses data from all 63 stations. receives some support from the lower number of photographs and recaptures obtained in Northern Kuamut, where no dominant males were recorded. It is also possible that Sunda clouded leopards cope well with forest disturbances as long as their prey base remains relatively stable. In all sites, prey species are still abundant and with no competition from other carnivores, and in the absence of hunting the Sunda clouded leopard will probably be able to survive in secondary forests. A study in Peninsular Malaysia found that mainland clouded leopard density in a logged forest was almost twice as high as in a primary forest, and prey availability was one of the most influential factors that determine clouded leopard density (Mohamad et al., 2015). Although Sunda clouded leopards appear to be somewhat resilient to logging, they are susceptible to hunting (Hearn et al., 2017). Poaching appeared to occur at very low levels in our sites, but in many other areas hunting levels increase with logging, as poachers benefit from easier access to the forest (Kleinschroth \& Healey, 2017). Hunting levels in Sabah have increased in the last decade, driven by the international demand for wildlife products. Reducing access to the forest interior by guarding road gates and patrolling potential entry points is therefore necessary to keep hunting levels low (Hearn et al., 2017) and allow the Sunda clouded leopard and other wildlife populations to persist in these forests.

Acknowledgements We thank the Sabah Biodiversity Center for issuing a research permit, the Sabah Forestry Department for its support, local research assistants, John Mathai and others involved in fieldwork. This project received financial support from the German Federal Ministry of Education and Research (BMBF FKZ: 01LN1301A), Point Defiance Zoo and Aquarium through the Dr. Holly Reed Conservation Fund, and San Francisco Zoo.

Author contributions Study conception and design, data analysis, writing: AM, RS, AW; fieldwork: AM, STW, JN, with logistical assistance from JK; assistance with data analysis and visualization: JFA; revisions: all authors.

Conflict of interest None.
Ethical standards This research abided by the Oryx guidelines on ethical standards.

\section{References}

Borchers, D.L. \& Efford, M.G. (2008) Spatially explicit maximum likelihood methods for capture-recapture studies. Biometrics, 64, 377-385.

Bowler, M.T., Tobler, M.W., Endress, B.A., Gilmore, M.P. \& Anderson, M.J. (2016) Estimating mammalian species richness and occupancy in tropical forest canopies with arboreal camera traps. Remote Sensing in Ecology and Conservation, 3, 146-157.

Brodie, J.F. \& Giordano, A.J. (2012) Density of the Vulnerable Sunda clouded leopard Neofelis diardi in a protected area in Sabah, Malaysian Borneo. Oryx, 46, 427-430.

Cheyne, S.M., Stark, D.J., Limin, S.H. \& Macdonald, D.W. (2013) First estimates of population ecology and threats to Sunda clouded leopards Neofelis diardi in a peat-swamp forest, Indonesia. Endangered Species Research, 22, 1-9.

Cubaynes, S., Pradel, R., Choquet, R., Duchamp, C., Gaillard, J.M., LEBRETON, J.D. et al. (2010) Importance of accounting for detection heterogeneity when estimating abundance: the case of French wolves. Conservation Biology, 24, 621-626.

Dillon, A. \& Kelly, M.J. (2008) Ocelot home range, overlap and density: comparing radio telemetry with camera trapping. Journal of Zoology, 275, 391-398.

EfFord, M.G. (2016) Spatially explicit capture-recapture. $R$ package version 2.10.4. Http://cran.r-project.org/web/package/secr/index. html [accessed 7 January 2017].

Efford, M.G. \& Fewster, R.M. (2013) Estimating population size by spatially explicit capture-recapture. Oikos, 122, 918-928.

Efford, M.G., Borchers, D.L. \& Byrom, A.E. (2009) Density estimation by spatially explicit capture-recapture: likelihood-based methods. In Modeling Demographic Processes in Marked Populations (eds D.L. Thomson, E.G. Cooch \& M.J. Conroy), pp. 255-269. Springer, New York, USA.

Gaveau, D.L.A., Wandono, H. \& Setiabudi, F. (2007) Three decades of deforestation in southwest Sumatra: have protected areas halted forest loss and logging, and promoted re-growth? Biological Conservation, 4, 495-504.

Gaveau, D.L.A., Sheil, D., Husnayaen, Salim, M.A., Arjasakusuma, S., Ancrenaz, M. et al. (2016) Rapid conversions 
and avoided deforestation: examining four decades of industrial plantation expansion in Borneo. Scientific Reports, 6, 32017.

Hearn, A., Sanderson, J., Ross, J., Wilting, A. \& Sunarto, S. (2008) Neofelis diardi ssp. borneensis. In The IUCN Red List of Threatened Species 2008: e.T136945A4351615. Http://dx.doi.org/10. 2305/IUCN.UK.2008.RLTS.T136945A4351615.en [accessed 15 July 2017].

Hearn, A.J., Ross, J., Pamin, D., Bernard, H., Hunter, L. \& MACDONALD, D.W. (2013) Insights into the spatial and temporal ecology of the Sunda clouded leopard Neofelis diardi. Raffles Bulletin of Zoology, 61, 871-875.

Hearn, A., Ross, J., Brodie, J., Cheyne, S., Haidir, I.A., Loken, B. et al. (2015) Neofelis diardi. In The IUCN Red List of Threatened Species 2015: e.T136603A97212874. Http://dx.doi.org/10.2305/IUCN. UK.2015-4.RLTS.T136603A50664601.en [accessed 15 July 2017].

Hearn, A.J., Ross, J., Macdonald, D.W., Bolongon, G., Cheyne, S.M., Moh amed, A. et al. (2016) Predicted distribution of the Sunda clouded leopard Neofelis diardi (Mammalia: Carnivora: Felidae) on Borneo. Raffles Bulletin of Zoology, Supplement No. 33, 149-156.

Hearn, A.J., Ross, J., Bernard, H., Bakar, S.A., Goossens, B., Hunter, L.T.B. \& Macdonald, D.W. (2017) Responses of Sunda clouded leopard Neofelis diardi population density to anthropogenic disturbance: refining estimates of its conservation status in Sabah. Oryx, published online 27 September 2017.

Howe, E.J., Овbаrd, M.E. \& Kyle, C.J. (2013) Combining data from 43 standardized surveys to estimate densities of female American black bears by spatially explicit capture-recapture. Population Ecology, 55, 595-607.

Jenny, D. (1996) Spatial organization of leopards Panthera pardus in Tai National Park, Ivory Coast: is rainforest habitat a 'tropical haven'? Journal of Zoology, 240, 427-440.

Karanth, K.U. \& SUnquist, M.E. (2000) Behavioural correlates of predation by tiger (Panthera tigris), leopard (Panthera pardus), and dhole (Cuon alpinus) in Nagarahole, India. Journal of Zoology, 250, 255-265.

Karanth, K.U., Nichols, J.D., Kumar, N.S. \& Hines, J.D. (2006) Assessing tiger population dynamics using photographic capturerecapture sampling. Ecology, 87, 2925-2937.

Kleinschroth, F. \& Healey, J.R. (2017) Impacts of logging roads on tropical forests. Biotropica, 49, 620-635.

Lagan, P., Mannan, S. \& Matsubayashi, H. (2007) Sustainable use of tropical forests by reduced-impact logging. Ecological Research, 22, 414-421.

Larrucea, E.S., Brussard, P.F., Jaeger, M.M. \& Barrett, R.H. (2006) Cameras, coyotes, and the assumption of equal detectability. Journal of Wildlife Management, 71, 1682-1689.

Mohamad, S.W., Rayan, D.M., Christopher, W.C.T., Hamirul, M., Mohamed, A., Lau, C.F. \& Siwan, E.S. (2015) The first description of population density and habitat use of the mainland clouded leopard Neofelis nebulosa within a logged primary forest in South East Asia. Population Ecology, 57, 495-503.

Niedballa, J., Sollmann, R., Courtiol, A. \& Wilting, A. (2016) CamtrapR: an $R$ package for efficient camera trap data management. Methods in Ecology and Evolution, 7, 1457-1462.

Otis, D.L., Burnham, K.P., White, G.C. \& Anderson, D.R. (1978) Statistical Inference from Capture Data on Closed Animal
Populations. Wildlife Monographs Series, no. 62. The Wildlife Society, Bethesda, USA.

Pledger, S. (2000) Unified maximum likelihood estimates for closed capture-recapture models using mixture. Biometrics, 56, 434-442.

R CORE TeAm (2017) R: a Language and Environment for Statistical Computing. R Foundation for Statistical Computing, Vienna, Austria.

Singh, R., Qureshi, Q., Sankar, K., Krausman, P.R. \& Goyal, S.P. (2014) Evaluating heterogeneity of sex-specific capture probability and precision in camera-trap population estimates of tigers. Wildlife Society Bulletin, 38, 791-796.

Sollmann, R., Malzoni, M., Gardner, B., Hofer, H., Jácomo, A.T.A., Mundim, N. \& Silveira, L. (2011) Improving density estimates for elusive carnivores: accounting for sex-specific detection and movements using spatial capture-recapture models for jaguars in central Brazil. Biological Conservation, 144, 1017-1024.

Sollmann, R., Gardner, B. \& Belant, J.L. (2012) How does spatial study design influence density estimates from spatial capture-recapture models? PLOS ONE, 7, e34575.

Sollmann, R., Linkie, M., Haidir, I.A. \& Macdonald, D.W. (2014) Bringing clarity to the clouded leopard Neofelis diardi: first density estimates from Sumatra. Oryx, 48, 536-539.

Sun, C.C., Fuller, A.K. \& Royle, J.A. (2014) Trap configuration and spacing influences parameter estimates in spatial capture-recapture models. PLOS ONE, 9, e88025.

Sunarto, Sanderson, J. \& Wilting, A. (2008) Neofelis diardi ssp. diardi. In The IUCN Red List of Threatened Species 2008: e.T136866A434769o. Http://dx.doi.org/10.2305/IUCN.UK.2008. RLTS.T136866A4347690.en [accessed 15 July 2017].

Tobler, M.W. \& Powell, G.V.N. (2013) Estimating jaguar densities with camera traps: problems with current designs and recommendations for future studies. Biological Conservation, 159, 109-118.

Tobler, M.W., Carrillo-Percastegui, S.E., Zúñiga Hartley, A. \& Powell, G.V.N. (2013) High jaguar densities and large population sizes in the core habitat of the southwestern Amazon. Biological Conservation, 159, 375-381.

Wearn, O.R., Rowcliffe, J.M., Carbone, C., Bernard, H. \& Ewers, R.M. (2013) Assessing the status of wild felids in a highly-disturbed commercial forest reserve in Borneo and the implications for camera trap survey design. PLOS ONE, 8, e77598.

Wilting, A., Mohamed, A., Ambu, L.N., Lagan, P., Mannan, S., Hofer, H. \& Sollmann, R. (2012) Density of the Vulnerable Sunda clouded leopard Neofelis diardi in two commercial forest reserves in Sabah, Malaysian Borneo. Oryx, 46, 423-426.

Wilton, C.M., Puckett, E.E., Beringer, J., Gardner, B., Eggert, L.S. \& BELANT, J.L. (2014) Trap array configuration influences estimates and precision of black bear density and abundance. PLOS ONE, 9, e111257.

Zimmermann, F., Breitenmoser-Würsten, C., Molinari-Jobin, A. \& Breitenmoser, U. (2013) Optimizing the size of the area surveyed for monitoring a Eurasian lynx (Lynx lynx) population in the Swiss Alps by means of photographic capture-recapture. Integrative Zoology, 8, 232-243. 